\title{
QUESTÕES SOBRE IDENTIDADE TERRITORIAL CAIÇARA E TURISMO DE BASE LOCAL
}

\author{
QUESTIONS SUR L'IDENTITÉ TERRITORIALE CAIÇARA ET \\ TOURISME DE BASE LOCALE \\ QUESTIONS ON CAIÇARA TERRITORIAL IDENTITY AND LOCAL \\ BASED TOURISM
}

\section{Maria del Carmen Matilde Huertas Calvente}

Doutora em Geografia - Universidade de São Paulo - Docente do Departamento de Geociências da Universidade Estadual de Londrina

Rodovia Celso Garcia Cid - PR 445 Km 380, s/n - Campus Universitário, Londrina - PR, 86057-970. E.mail: calvente@uel.br

\begin{abstract}
Resumo
O objetivo deste artigo é trazer reflexões sobre a compreensão do conceito de identidade e, a partir daí, de identidade territorial, em relação aos lugares de vivência das populações tradicionais que tenham se tornados turísticos, com um estudo de caso no Município de Ilhabela, Estado de São Paulo, Brasil, no bairro/praia do Curral, através de entrevistas qualitativas e análise da memória em relação ao lugar. Utilizando-se observação, análise das entrevistas e discussão teórica, entende-se que populações tradicionais podem ser alvos de estereótipos e preconceitos em um turismo excludente e que devem ser apoiadas na sua identidade territorial para que estas populações possam manter seu território, passando de uma identidade de resistência para uma identidade de projeto, na ideia de turismo com base local.
\end{abstract}

Palavras-chave: Identidade Territorial - Turismo - Populações Tradicionais - Ilhabela/SP

\section{Résumé}

Le but de cet article est d'apporter des réflexions sur la compréhension de la notion d'identité et, de là, de l'identité territoriale par rapport aux lieux de vie des populations traditionnelles qui sont devenus touristique, avec une étude de cas dans la ville de Ilhabela, État São Paulo, au Brésil, dans le quartier / plage du Curral, à travers des entretiens qualitatifs et l'analyse de la mémoire par rapport à l'endroit. En utilisation de l'observation, de l'analyse des entretiens et discussion théorique, on comprend que les communautés traditionnelles peuvent être la cible de stéréotypes et de préjugés dans un tourisme exclusif et doivent être soutenus dans leur identité territoriale tant dans les politiques publiques quant à des projets visant que cette populations puisse maintenir leur territoire, passant d'une identité de résistance à une identité de projet dans l'idée d'un tourisme basé localement.

Mots-clés: L'Identité Territoriale - Tourisme - Populations Traditionnelles - Ilhabela / SP 


\section{Abstract}

The objective of this article is to encourage some reflections on the identity concept, and, thereafter, on the territorial identity related to places inhabited by traditional populations that have become tourist destinations, through a case study developed at the Ilhabela County, São Paulo State, Brazil, in the Curral neighborhood/beach, using qualitative interviews and memory analysis in relation to the place. By adopting observations, interview analysis and theoretical discussions, it was understood that traditional populations can become targets of stereotyping and prejudice in an excluding tourism, and that they must be supported in their territorial identity so that they can maintain their territory, moving from a resistance identity to a project identity, within the idea of tourism with a local basis.

Keywords:Territorial Identity - Tourism - Traditional Populations - Ilhabela/SP 


\section{INTRODUÇÃO}

A discussão do artigo vai tentar compreender a identidade territorial de comunidades tradicionais e a importante relação desta identidade com o denominado turismo de base local. A questão surgiu há muito tempo, a partir da vivência da autora como professora de Geografia em uma comunidade caiçara, nas décadas de 1980 e 1990, que resultou em uma dissertação de mestrado (AUTOR, 1993) na qual se discutia a alteridade dos caiçaras e se esboçava uma ideia que se chamou, então, de consciência étnica.

O termo caiçara é usado como uma autodenominação para o natural do litoral no estado de São Paulo, em parte do litoral do Rio de Janeiro e em parte do litoral do Paraná. A palavra teve origem no tupi kai" sara; era o nome da estacada de proteção à volta das tabas ou aldeias indígenas.

$\mathrm{Na}$ época da dissertação de mestrado se estudou três bairros/praias de Ilhabela, município do Litoral Norte do Estado de São Paulo. Agora, para a pesquisa empírica fonte deste artigo, escolheu-se um dos três bairros (Curral) e entrevistou-se a população caiçara. Isso permitiu observar as transformações ocorridas no lugar após duas décadas de um primeiro estudo sobre os impactos do turismo. Portanto, trabalhou-se fundamentalmente com a memória da coletividade em um diálogo com a teoria. Entende-se a memória como um movimento entre racionalidades (palavras como construções carregadas de conceitos) e subjetividades, tanto individuais como coletivas.

No recorte temático deste texto, foi importante entender, através da pesquisa bibliográfica, a identidade, a identidade territorial, a identidade territorial caiçara, o turismo de base local e estabelecer relações entre esses conceitos a partir do que foi observado e das falas dos entrevistados.

\section{IDENTIDADE}

Na concepção de Castells (1999), há três formas de identidade: identidade legitimadora (introduzida pelas instituições dominantes para expandir e racionalizar sua dominação, como no nacionalismo); identidade de resistência (criada para resistir e sobreviver com base em princípios diferentes dos que permeiam as instituições sociais); e identidade de projeto (quando as pessoas constroem uma nova identidade que redefine sua posição na sociedade e, ao fazerem isto, buscam a transformação da estrutura social, como, por exemplo, o feminismo). É claro que as identidades, na dinâmica social, podem se transformar (de resistência em projeto, e de projeto em legitimadora). 
A identidade legitimadora dá origem a uma sociedade civil; a identidade de resistência forma comunidades. A de resistência é uma identidade defensiva em termos das instituições ou ideologias dominantes. A busca pelo significado, na identidade de resistência, ocorre no âmbito da reconstrução defensiva de significados em torno dos princípios comunais.

Assim, surgiu o paradoxo de forças políticas com bases cada vez mais locais em um mundo estruturado por processos cada vez mais globais. Houve a produção de significado e identidade: minha vizinhança, minha comunidade, minha cidade, minha escola, minha árvore, meu rio, minha praia, minha capela, minha paz, meu ambiente. Contudo, essa foi uma identidade defensiva, uma identidade de entrincheiramento no que se entende como conhecido contra a imprevisibilidade do desconhecido e do incontrolável. (CASTELLS, 1999, p. 80)

Esclarecendo melhor, o autor (1999, p. 23) distingue entre papel (trabalhador, mãe, vizinho etc.) e identidade. O papel é definido externamente, por normas de instituições e da sociedade. Já a identidade origina-se internamente. "Em termos mais genéricos, podese dizer que identidades organizam significados, enquanto papéis organizam funções”. Assim, as atividades tradicionais caiçaras - pesca e agricultura - criam papéis, mas não a identidade.

A construção da identidade usa a matéria-prima fornecida pela memória coletiva e por fantasias das pessoas, mas essa matéria-prima é processada pelos indivíduos e grupos sociais, que reorganizam seu significado.

É importante também diferenciar identidade social de identidade territorial, esta última de extrema importância nos estudos geográficos. A identidade territorial:

[...] é uma identidade definida fundamentalmente através do território, ou seja, dentro de uma relação de apropriação que se dá tanto no campo das idéias quanto no da realidade concreta, o espaço geográfico constituindo assim parte fundamental dos processos de identificação social. Se toda identidade territorial é, obviamente, uma identidade social, nem toda identidade social (como a identidade de gênero, por exemplo) toma, obrigatoriamente, como um dos seus referenciais centrais, o território ou, num sentido mais restrito, uma fração do espaço geográfico. (HAESBAERT, 1999, p. 172)

\section{IDENTIDADE TERRITORIAL CAIÇARA}

Com base em tais reflexões procurou-se entender qual é a leitura que o caiçara faz de ser caiçara e como eles percebem que são vistos pelos não caiçaras. A identidade caiçara é uma identidade territorial de resistência simbólica, mais relacionada ao passado que as possibilidades de um futuro. Nas respostas à questão formulada "O que é ser caiçara, para esta família? Como vocês percebem que quem é de fora vê os caiçaras?", elementos da configuração territorial estão na quase totalidade das respostas. 
A pesquisa científica que usa as narrativas dos sujeitos entrevistados depara-se com uma questão fundamental. Antes de tudo, é importante ter claro que a narrativa não é uma "fidedigna descrição dos fatos", tais como eles realmente ocorreram. Os relatos que são narrados são representações da realidade, prenhes de significados e reinterpretações, e são esses significados que dão riqueza à análise. Para Abrahão (2003 p.80):

[...] o pesquisador conscientemente adota uma tradição em pesquisa que reconhece ser a realidade social multifacetária, socialmente construída por seres humanos [...]. Por esta razão, sabe-se, desde o início, trabalhando antes com emoções e intuições do que com dados exatos e acabados; com subjetividades, portanto, antes do que com o objetivo. Nesta tradição de pesquisa, o pesquisador [pretende...] compreender o fenômeno de estudo, o que lhe pode até permitir uma generalização analítica.

Portanto, o que importava, nestas primeiras questões, era entender o significado que os sujeitos entrevistados davam ao "ser caiçara" em um esforço de generalização analítica e, dos 32 entrevistados, apenas um não usou os elementos do território na sua resposta (quadro 1). Respondeu que "ser caiçara é muito orgulho", de forma lacônica. Na ocasião, a resposta não foi explorada, mas, se o fosse, provavelmente se chegaria também a elementos da configuração territorial.

Quadro 1 - Análise das respostas dadas na questão, relacionando-as aos elementos da configuração territorial

\begin{tabular}{cl}
\hline Elementos do território e da cultura na resposta & 18 \\
\hline Apenas elementos do território & 09 \\
\hline Apenas elementos da cultura & 01 \\
\hline Não sabe/não respondeu & 04 \\
\hline
\end{tabular}

Fonte: Autor, 2011

Entende-se que a identidade territorial possui dimensões subjetivas, mas, diferentemente da identidade individual, a dimensão da paisagem vai aparecer de forma nítida, já que: “[...] por mais que se reconstrua simbolicamente um espaço,sua dimensão maisconcreta constitui, de alguma forma, um componente estruturador da identidade" (HAESBAERT, 1999, p. 174 - grifo do autor). E utilizar a memória para compreender a identidade territorial parece fundamental, já que as narrativas são: “[...] repletas de experiências vividas, de socialização das tradições, de sensibilidades, de histórias individuais construídas na história coletiva, de pessoas localizadas num determinado lugar e é deste que falam, sentem, rememoram, significam e ressignificam" (MARTELLI, 2007, p. 7 - 8). Como se pôde observar, a auto identificação caiçara é constantemente acompanhada de uma visão positiva: 
O que é ser caiçara? Sei lá o que é, o que eu posso te responder? O que é ser caiçara... sei lá. Para mim é um orgulho ser caiçara, sei lá, viver em um lugar desses, desfrutar de tudo o que a gente tem aqui. Sou caiçara, acho que o que determina a pessoas ser caiçara é o lugar onde nasce, na beira do mar, eu acho que é isso. (entrevistado 1)

Observa-se, na fala acima transcrita, o reforço de uma regularidade que emergiu ao longo das entrevistas: a identidade caiçara é assumida, essencialmente, como reflexo de uma estruturação lógica entre homem x natureza em que o primeiro não se define através de uma hierarquização sobressalente ao meio. É neste sentido que se fala em "desfrutar" da riqueza natural, e não em aproveitar esta riqueza para gerar outra, de configuração bastante diversa.

Para sete pessoas, quase um quarto dos entrevistados, fica patente que o "ser caiçara" traz um sentimento de orgulho. Mas, já que: "Ao envolver um processo de classificação e/ ou de distinção, a identificação social legitima um existir social no qual a percepção das diferenças é fundamental para a afirmação do grupo cultural” e que: “Toda identidade só se define em relação a outras identidades, numa relação complexa de escalas territoriais e valorações negativas e positivas" (HAESBAERT, 1999, p. 175) torna-se importante saber também como os caiçaras percebem que são valorados pelos "turistas" (no Curral a pessoa não nativa, morando ou não na ilha, recebe esta denominação).

Alguns conceitos podem tornar mais claro o que vai ser analisado neste momento: os de crença, estereótipo e preconceito. Para Leite (2008) as crenças podem ser definidas como aquilo que se aprende desde criança e se adota com verdade. Elas têm origem em experiências pessoais nas esferas da atenção, percepção, pensamento, raciocínio e imaginação e se formam por associação, nas mediações de relacionamento e aprendizagem. Podem ser pessoais (um julgamento pessoal a respeito de alguém) ou compartilhadas (opinião pública ou estereótipos sociais).

Já os estereótipos são fruto da capacidade de síntese, condensando elementos plurais em uma imagem - uma crença compartilhada coletivamente, em um esforço de simplificação. A palavra é formada por stereos (palavra grega para rígido) e túpos (significando traço). Traços rígidos são imputados a pessoas de determinados grupos sociais, que assim são organizados na mente do indivíduo, tornando menos complexo o ambiente social. Frequentemente há discrepâncias entre as características atribuídas e as verdadeiras.

Os estereótipos sociais são divididos, por uma matriz relacional de atributos positivos e negativos e também em auto-estereótipo e hétero-estereótipo (focado em grupo distinto do qual o indivíduo pertence). Por fim, os preconceitos sociais são definidos como uma atitude negativa e injusta derivada de estereótipos. Para Leite (2008, p. 135) “Dessa forma, 
o preconceito pode ser compreendido como uma opinião prévia, que se problematiza por um julgamento antecipado, sem base de juízos de valor, a respeito de um indivíduo/grupo de forma discriminatória”.

Diante do questionamento acerca do que os caiçaras creem que os identifica (autoestereótipo), chegou-se a uma predominância de respostas que relacionam o ser caiçara a elementos materiais e simbólicos como o local de nascimento e a adjetivação do sentimento de fazer parte do grupo. O primeiro caso recebeu 16 de um total de 68 menções. Um nível de análise abaixo, esta vinculação do ser caiçara ao local de nascimento subdivide-se em 12 menções que se referem ao "nascer à beira mar, no litoral" e quatro menções cuja gênese é mais localizada, nas quais se relaciona a identidade ao "nascer em Ilhabela", especificamente.

Já no caso da relação equivalente entre o ser caiçara e a valoração do sentimento de pertença, chegou-se, também, a 16 menções, cujas especificidades incluem sete denotações vinculadas a "orgulho", cinco menções ao fato de ser "bom" fazer parte do grupo e duas menções sintetizando o ser caiçara na expressão "tudo".

O restante das 68 informações obtidas torna ainda mais clara a lógica que organiza a auto definição dos caiçaras conectando-a, na maior parte das vezes simultaneamente, tanto a elementos que indicam a escala simbólica da identidade territorial quanto a elementos que convidam a uma perspectiva material. Isto se observa nas 11 menções para a relação entre identidade e "atividades", oito para "estilo de vida", oito para a relação entre identidade e os "elementos da paisagem natural", sete definições identitárias retiradas da "relação com o lugar" e duas inferidas nas "características culturais" do grupo.

Uma análise com um nível ainda maior de detalhe mostra que a palavra "nascimento" apareceu 21 vezes ao longo das falas que objetivavam a definição da identidade caiçara. $\mathrm{O}$ termo "praia", por seu turno, foi utilizado 11 vezes, mesma quantidade de ocasiões em que se ouviu a palavra "aqui" (neste lugar), marcando um profundo enraizamento simbólicomaterial entre grupo e território.

Foram consideradas apenas as palavras cuja menção ocorreu mais de uma vez, sendo que em um universo de análise de 71 palavras com significado definidor, aquelas que foram citadas no parágrafo anterior representam mais da metade.

Quando se trata de projetar o significado da identidade caiçara para aqueles que não pertencem a este grupo (hétero-estereótipo), passando pelo filtro valorativo dos próprios caiçaras, observa-se a predominância de relações que engendram adjetivações pejorativas (preconceito). Das 69 atribuições, pôde-se relacionar 35, ou seja, com uma pequena maioria, 
a visões consideradas negativas. Visões positivas foram expressas em 22 casos, e atribuições neutras corresponderam a 12 casos.

Ciconello (2008, p. 1), ao discutir o racismo no Brasil, apresenta uma pesquisa na qual $87 \%$ dos brasileiros admitem que o racismo existe no pais, mas apenas $4 \%$ se consideram racistas. Uma análise dos dados chegou à seguinte conclusão: “[...] o racismo existe não pela consciência de quem o exerce, mas sim pelos efeitos de quem sofre [...] embora perceptível, se localiza sempre no outro, nunca nas práticas cotidianas de seus agentes, o que torna ainda mais difícil sua superação". Assim, as afirmações dos caiçaras sobre como são vistos por pessoas de fora do grupo revelam melhores possibilidades para compreender a questão.

A maioria, isto é, aqueles que afirmaram que os "de fora" enxergam os caiçaras de uma forma preconceituosa, têm suas opiniões ramificadas nas seguintes relações: $i$. comportamento (dez menções, sendo seis delas aclaradas através da palavra "preguiça"); ii. inteligência(nove menções, sendo cinco delas adjetivadas através do termo "ignorância”); iii. modo de vida (sete menções: duas para "atrasados" e duas para "bicho do mato"); iv. convívio(cinco ocorrências subdivididas em duas informações de uma certa "superioridade" com que os "de fora" veem os caiçaras); e, por fim, v. situação econômica (também cinco menções, três delas sintetizadas através da expressão "carência").

No que tange às visões positivas, 14 das 22 ocorrências estão relacionadas ao convívio, sendo que sete estão generalizadas na palavra "admiração" e cinco na palavra "respeito". Nas atribuições neutras, ou seja, aquelas em que não se chegou à evidência da valoração negativa ou positiva, a totalidade (12 menções) está vinculada a uma relação com o modo de vida, quatro caiçaras declarando que os de fora os veem "indistintamente", três afirmando que a única diferenciação entre uns e outros é o "sotaque", e dois relacionando esta alteridade à palavra "caipira", como definição do caiçara para os turistas.

Em resumo, se o auto-estereótipo é tão positivo, no hétero-estereótipo os caiçaras observam o preconceito, passível de ser observado na utilização de palavras como: trouxa, preguiçoso, esquisito, bobo, bicho e descansado. Citadas por apenas um entrevistado, outras palavras pejorativas foram usadas: ruim, receio, pobre, orgulhoso, matuto, malandro, indolente, ignorante, empregado, desleixado, danado, coitado, carente, burro e atrasado. Tentou-se diferenciar as respostas com outro cruzamento (quadro 2), analisando a última resposta, por entrevistado, entre positiva, negativa, ambos e neutra. 
Quadro 2- Conotação das respostas

\begin{tabular}{cl}
\hline Conotação apenas negativa & 10 \\
\hline Conotação positiva e negativa & 07 \\
\hline Conotação neutra & 07 \\
\hline Conotação apenas positiva & 06 \\
\hline Não sabe/não respondeu & 02 \\
\hline
\end{tabular}

Fonte: Autor, 2011

Para compreender o contexto no qual o preconceito é compreendido, é necessário também entender o humor e certa ironia que apareciam nas respostas dos entrevistados. A resposta da entrevistada 2 é um bom exemplo:

A maior parte, que eu discordo, chama o caiçara de indolente, mas - veja bem - essa indolência não é pelo fato dele ser preguiçoso, porque gerou... Esse termo é quase que uma palavra meio dúbia de ser, mas não porque ele é preguiçoso, veja bem, quem come um pirão de banana verde com um bom peixe, ele não vai deixar de dar uma soneca depois do almoço para depois ir trabalhar, esse prato fez com que o pessoal colocasse esse nome de preguiçoso para o caiçara, o que não é, porque eu sou caiçara e me considero trabalhadeira. E a maior parte dos meus irmãos, a maior parte dos caiçaras é trabalhador, só que gerou essa confusão, essa história pela indolência, mas é pela alimentação dele, não é? Numa comunidade atrás da ilha, isolada, o que o cara vai fazer? Come pirão de banana e vai para a roça? Não vai, ele vai tirar uma soneca na rede, na praia, na canoa e depois vai trabalhar, não é? Não tem horário para nada.

No período do trabalho de campo, estava acontecendo em Ilhabela mais uma "Semana Internacional da Vela", quando ocorrem vários eventos culturais na "vila" (área central do município); entre eles, na época, assistiu-se a uma peça teatral produzida com base nas histórias contadas pelos mais velhos sobre "causos" ocorridos com famílias caiçaras, na década de 1950 (figura 1). Foi esse preconceito com relação aos caiçaras que apareceu na peça, como nas respostas da questão.

A peça teatral poderia ter outro teor? Entende-se que sim, na procura de diminuir o preconceito. Leite (2008), ao apresentar as chamadas propagandas contra-intuitivas (as que trazem situações que fazem as pessoas rever os seus conceitos) explica uma possibilidade de deslocar crenças e estereótipos através de um modelo teórico de supressão do pensamento, que orienta o individuo receptor mediante a sua própria reflexão sobre as crenças sociais produtoras de estereótipos. Isto é, após receber uma mensagem contra-intuitiva, a pessoa pode reavaliar e contrabalancear suas crenças, possibilitando a esta pessoa agregar uma nova associação ou uma substituição. E Ciconello (2008) afirma que a superação das desigualdades, paralelamente a implantação das políticas públicas, deve passar por uma batalha comunicativa, de modo a desmanchar os estereótipos e os preconceitos. 
FIGURA 1 - Os caiçaras na visão teatral

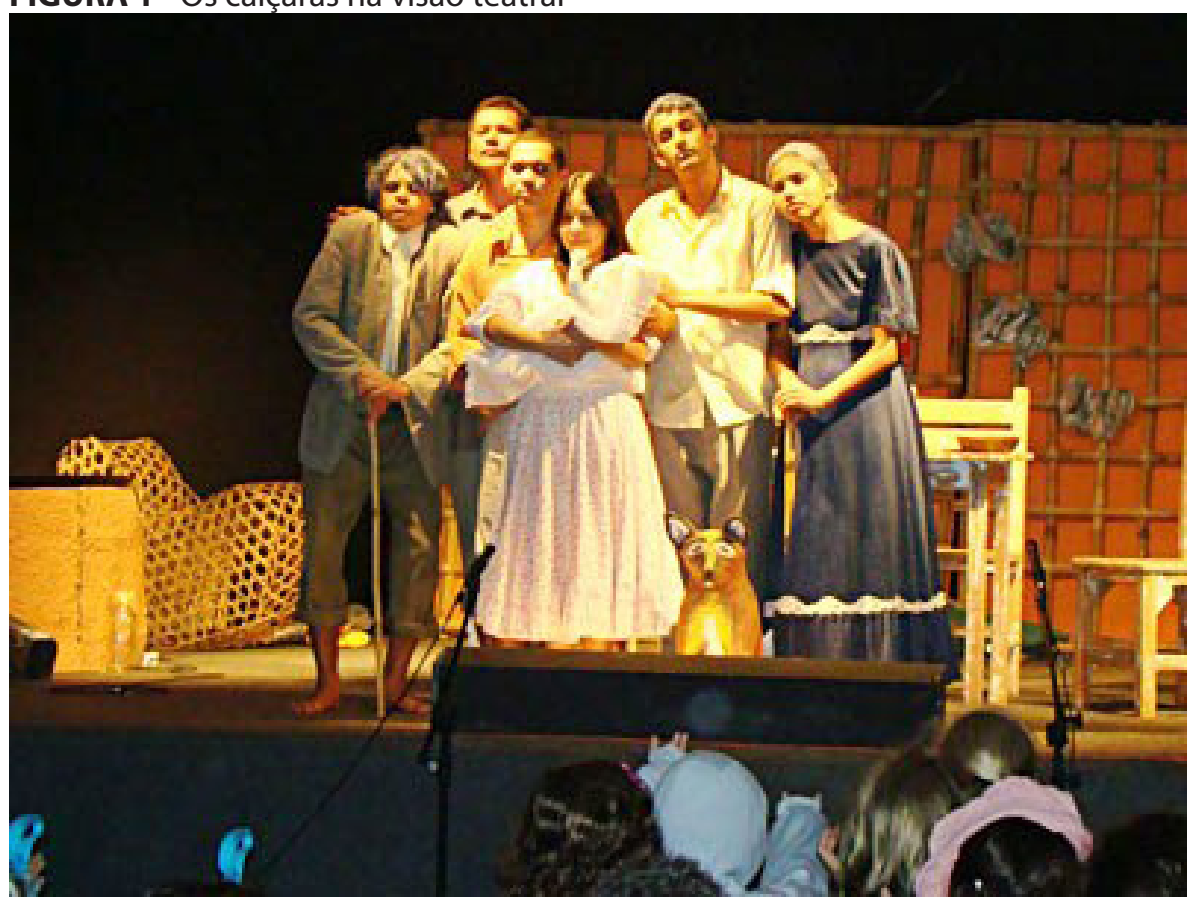

Fonte: Ihabela, $2011 a$.

Mesmo que em forma de resquício, e apesar do preconceito, constatou-se a identidade territorial caiçara como uma forma de resistência, inclusive pela relação entre o "ser caiçara” e ser discriminado pela pobreza: “Tem uns que veem como sinceros; não mentem, humildes, corretos com o que fazem. Outros já têm certa discriminação, por causa que somos pobres" (entrevistado 3); "Depende, porque tem muitas pessoas que respeitam a gente como morador, agora têm outros que não, que acha que porque têm dinheiro são donos do lugar [...]" (entrevistada 4); "Eu penso comigo que eles veem assim, nós aqui somos empregados deles, eles pensam isso dos nativos mesmos, dos caiçaras que são poucos, porque hoje é mais gente de fora do que os próprios caiçaras" (entrevistado 5).

Contextualizando o início desta relação (moradores caiçaras X turistas), foi com a abertura da estrada de rodagem São Sebastião - São Paulo (em 1935) que chegaram os primeiros e poucos turistas para as férias de verão ou feriados prolongados no município. É desencadeado, assim, o processo de urbanização, com o aparecimento das segundas residências e a melhoria do equipamento do antigo núcleo (FRANÇA, 1951). Nas décadas seguintes, com o processo de intensa industrialização de São Paulo, a atividade turística deixa de existir para alguns poucos e começa a surgir o turismo de massas: aparece uma demanda para um projeto turístico na região. 
A estrada de rodagem São Sebastião - São Paulo é asfaltada, é inaugurado o Terminal Petroleiro de São Sebastião e também uma linha de balsas que liga a ilha ao continente, tornando possível a chegada de automóveis. Estas ações são realizadas dentro de uma política nacional, denominada rodoviarismo, em um processo histórico mais amplo, que atinge toda a América Latina. O Brasil abre as portas para o capital estrangeiro, acelera-se o processo de industrialização de São Paulo e arredores, com a instalação de multinacionais, as indústrias automobilísticas, mecânicas, químicas etc. Aumenta o numero de brasileiros com o hábito de viajar de férias no seu automóvel, dentro de valores sociais que os meios de comunicação acabam impondo como qualidade de vida, e que são fortemente enraizados nos interesses econômicos, pois estava ocorrendo a implantação da indústria automobilística no país.

A maior parte desta faixa litorânea ficou relativamente isolada das transformações que ocorriam nas grandes cidades até a década de 1970: os habitantes sobreviviam através de uma agricultura de subsistência, combinada com a pesca artesanal ou autônoma e algumas relações comerciais com cidades maiores, como Santos. As atividades agrícolas de subsistência e a pesca artesanal implicam uma relação forte com o mundo natural, permitindo a criação de um saber popular específico com relação a estes lugares, saber que era transmitido e modificado através de gerações (CALVENTE, 1993).

O abandono da pesca e da agricultura de subsistência aparece como perda nostálgica de um tempo passado do caiçara, tendo como exemplos: "A maioria não pesca e nem trabalha mais na roça" (entrevistado 6); "Antes era quem vivia da pesca, da terra, do que plantava, do artesanato. Hoje ninguém vive mais do que planta, pesca, nem do artesanato" (entrevistada 7); "Hoje não podemos viver mais da pesca e nem da terra. Hoje nem temos mais onde colocar os barcos, se você colocar barcos lá o pessoal do hotel tira, e se você colocar novamente, eles queimam" (entrevistado 8).

Para Martelli (2007, p. 5 - 6) “[...] a opção pela narrativa nos compele a uma coragem intelectual para ouvir as vozes de pessoas anônimas e suas experiências e memória [...]”. Por isso, importante destacar que, para o próprio grupo, conforme as respostas, o fato de deixarem as atividades tradicionais não significa a perda da identidade territorial, como pode ser entendido pelo senso comum. Pelo contrário, o processo territorial ocorrido com o turismo pode fortalecer a identidade, por que:

Para os atores sociais excluídos ou que tenham oferecido resistência à individualização da identidade relacionada à vida nas redes globais de riqueza e poder, as comunas culturais de cunho religioso, nacional ou territorial parecem ser a principal alternativa para a construção de significados em nossa sociedade. [...] organizadas em torno de um conjunto específico de valores cujo significado e uso compartilhado são marcados por códigos específicos de auto-identificação [...]." (CASTELLS, 1999, p. 84) 
Entre esses códigos de auto identificação está a memória coletiva, um passado carregado de elementos do imaginário, uma história comum que auxilia na compreensão da identidade territorial e que pode auxiliar nas relações de poder locais e na autonomia de um grupo na decisão dos rumos do turismo. Mais frequentemente, a atividade turística vai ser imposta desconsiderando e desvalorizando as identidades e a história do lugar.

\section{TURISMO}

Rodrigues (2009), enfocando especificamente o turismo como prática social, chama de territórios zonais de resistência/inovação os que, apesar de articulados à rede regional e nacional, e, eventualmente, global, não estão hierarquicamente subordinados. São, prioritariamente, territórios de abrigo e recurso, com predomínio de relações de poder locais, com princípios ligados à autonomia. Infelizmente, não é este o caminho que o turismo está tomando no bairro do Curral, assim como na maioria dos locais que se tornaram turísticos, o que torna os territórios zonais de resistência/inovação quase que uma idealização.

No trabalho realizado há duas décadas, dos três bairros pesquisados no município o do Curral era o que apresentava maiores possibilidades para um turismo não excludente. $\mathrm{Na}$ época, diferentemente dos outros lugares pesquisados, o turismo era positivo na análise feita por que: [...] para o morador do Curral, viver do turismo não significa vender as terras para o turista [...] (AUTOR, 1993, p. 46). Segundo os entrevistados, os turistas eram os "amigos" e não os "patrões". Esta relação mudou, especialmente com a instalação de umresortna Praia do Curral no ano de 2009, mas também com outros processos da sociedade contemporânea. Assim, nas falas dos entrevistados, passado, presente e futurose entrelaçam, já que são:

[...] três planos de compreensão de contexto: o contexto vivido no passado, que comporta a totalidade de referenciais biográficos e sociais dos sujeitos entrevistados; o contexto do presente dos sujeitos, que supõe a rede de relações sociais do presente dos sujeitos, desde as que se elaboram mediante a concreta situação da entrevista estabelecendo seu sentido para o presente; o contexto da entrevista, que supõe as formas de acordo e cooperação para a efetivação da própria entrevista, como a relação de escuta e transmissão em reciprocidade como condição para a reflexão. (ABRAHÃO, 2003, pp. 82 - 83)

Se há 20 anos o turismo era visto por todos os entrevistados do Curral apenas como positivo, a intencionalidade do pesquisador era saber o que pensam os caiçaras do Curral hoje, após todo o processo de turistificação. Durante uma pesquisa qualitativa, como a realizada, as pessoas vão relatando suas experiências, crenças e expectativas, e, durante as falas, vão também desvendando o que entendem como novas possibilidades, as suas intenções e os seus projetos. Cunha (1997, p. 188) afirma que: "A trajetória da pesquisa 
qualitativa confirma o fato que tanto o relato da realidade produz a história como ele mesmo produz a realidade. [...] Ás vezes, torna-se difícil separar o vivido do que está para viver".

As respostas nas entrevistas atuais indicaram uma visão apenas positiva do turismo para 14 entrevistados (44\%). A maioria (17 pessoas ou 53\%) considera o turismo ambíguo, com aspectos bons e ruins, como a atividade realmente é em relação aos seus impactos. Há 20 anos o turismo era visto ainda sem a reflexão necessária, pois:

O sistema social, conscientemente, envolve as pessoas numa espiral de ação sem reflexão. Fazemos as coisas porque todos fazem, porque nos disseram que assim é que se age, porque a mídia estimula e os padrões sociais aplaudem, Acabamos agindo sobre o ponto de vista do outro, abrindo mão da nossa própria identidade, da nossa liberdade de ver a agir sobre o mundo, da nossa capacidade de entender e significar por nós mesmos. (CUNHA, 1997, p. 190)

A pergunta feita foi: "O turismo aqui é algo mais positivo ou negativo? No que é positivo e no que é negativo?" Os aspectos positivos abordados pelos entrevistados podem ser englobados pelos aspectos econômicos e os aspectos negativos pela falta de estrutura do lugar (10 menções); ambientais (nove menções, sendo que quatro são especificamente com relação ao lixo produzido); dificuldades na relação com os turistas (quatro menções); mudança no estilo de vida caiçara (três menções) e o fato do turismo ser sazonal (uma menção). Apenas um entrevistado entende o turismo só nos seus aspectos negativos, em razão de que o turismo tornou impossível viver da pesca. Fora este último, todos mencionaram que o turismo tem aspectos positivos. O quadro3vai mostrar os principais aspectos positivos e negativos, mas, como um exemplo específico, pode-se trazer antes a fala da entrevistada 9 , que mostra também o quanto a denominação ilha é carregada de simbolismo:

Positivo porque é muita porta de emprego, devido aos turistas ter casas, lanchas, precisam de jardineiros, faxineiros, motoristas, cozinheiros. Para as lanchas eles precisam de marinheiros, outrora não tinha, então o caiçara pescava, plantava, ou então tinha que ir para fora para ter um emprego e hoje não, trabalham aqui mesmo. Negativo essa agressividade com a própria natureza da ilha, você acaba deixando de ser uma ilha, o que é uma ilha? É terra, céu, mar, poucas casas e a natureza, isso é uma ilha, quando você vê muita casa, muita casa e muito comércio, vai acabar virando uma cidade e deixa de ser ilha, é o que eu acho. 
Quadro 3 - Aspectos positivos e negativos do turismo citados por mais de um entrevistado

\begin{tabular}{|c|c|c|c|}
\hline $\begin{array}{c}\text { Principais aspectos positivos } \\
\text { do turismo }\end{array}$ & & $\begin{array}{c}\text { Principais aspectos negativos } \\
\text { do turismo }\end{array}$ & \\
\hline Movimento para o comércio & 10 & Bagunça & 02 \\
\hline Geração de emprego & 09 & $\begin{array}{c}\text { Tamanho da ilha não comporta } \\
\text { quantidade de turistas }\end{array}$ & 02 \\
\hline Crescimento da renda & 08 & $\begin{array}{l}\text { Capacidade dos serviços não } \\
\text { comporta quantidade de turistas }\end{array}$ & 02 \\
\hline Traz riqueza & 03 & Caiçara perde seu espaço & 02 \\
\hline Maior venda de peixe & 03 & Vinda de gente ruim/má & 02 \\
\hline Progresso & 02 & & \\
\hline Traz ânimo ao lugar & 02 & & \\
\hline Traz movimento (em geral) & 02 & & \\
\hline
\end{tabular}

Fonte: Autor, 2011

É conveniente salientar, à luz da observação do conteúdo da fala anterior, que a dialética, a contradição expressa no ser, ao mesmo tempo, positiva e negativa a introdução do turismo em Ilhabela, é uma das características mais marcantes do capitalismo - no presente caso, transfigurado em atividade turística.

Isto porque aquilo que é bom (a criação de empregos) é igualmente ruim, pois são as lanchas, os automóveis, a proliferação de casas em cujos jardins trabalharão os caiçaras, e a proliferação de estabelecimentos comerciais em que estes serão mão-de-obra barata, "progresso" que permitirá aos caiçaras permanecerem na ilha, são estes mesmos elementos os responsáveis pela transfiguração da paisagem da ilha, pela agressão à natureza reclamada na entrevista.

Afinal, para que o lucro se efetive, não basta que a paisagem seja apropriada enquanto mercadoria. É necessária, também, uma infraestrutura que integre fixos e fluxos, essenciais à formação de um mercado consumidor. Desta maneira, a ilha deve continuar ilha, porque a paisagem insular é a mercadoria, mas deve também deixar de ser ilha, interagindo de maneira eficaz com as verticalidades através de serviços de acesso e mobilidade, de recurso ao meio técnico-científico informacional.

Não é de surpreender, portanto, que o processo de hegemonização do capital sobre o território de Ilhabela tenha se metamorfoseado. Quando a totalidade da ilha deixou de ser um produto atraente para alguns turistas, preocupados com o trânsito e a violência, por exemplo,

a 
foi necessário restringir um pouco mais esta “ilha”, limitando-a a uma porção de território da qual o poder econômico se apossa para reproduzir as condições que lhe permitiram o lucro. O bairro do Curral e as paisagens que ele revela (figura 2) são o melhor exemplo.

Figura 2 - Visão do por do sol da Capela de Santa Cruz, no Curral

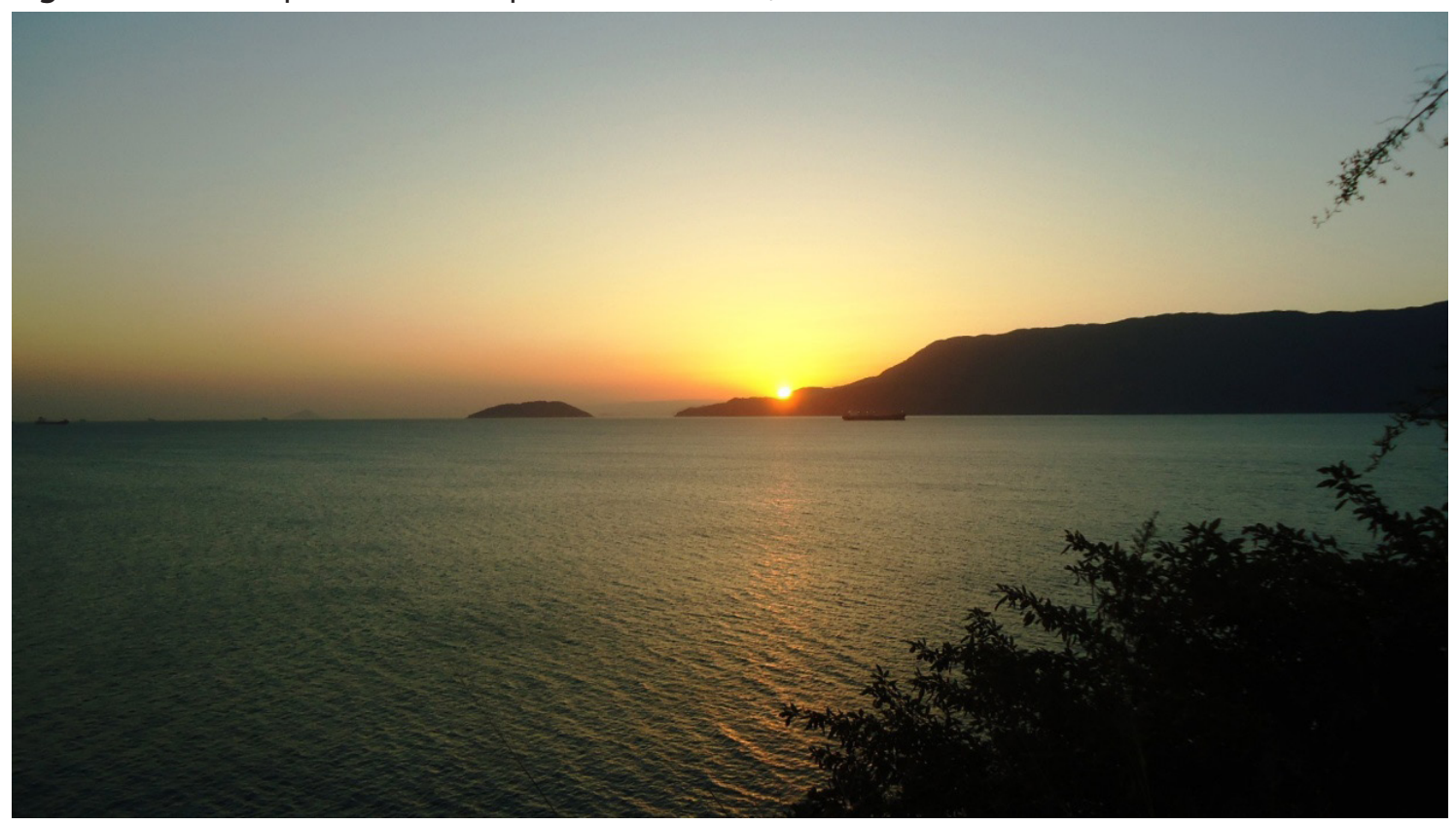

Autoria: Edi Santos, 2011

\section{BASE LOCAL}

De acordo com Rodrigues (2009) os territórios zonaisde resistência/inovação estão ligados a um modelo peculiar de origem, na interação entre sujeitos locais, características naturais, infraestrutura e cooperação. Deles emana o sentido de pertencimento, a consciência territorial. Para a autora, é nos territórios zonais de resistência/inovação que estão se desenvolvendo os principais projetos de turismo com base local no Brasil. Estes territórios são de inovação não no sentido de inovação tecnológica, mas no sentido da produção de algo novo no lugar. Ao esclarecer uma dúvida pontual que surgiu com a leitura de um artigo relacionado ao turismo para a inserção social (RODRIGUES, 2009), escreveu Rodrigues $(2011$, p. 1):

[...] somente resistência poderia significar, simplesmente, congelamento. A idéia é de que haja também inovações, na luta pelo que necessitam para conservação da biodiversidade e sociodiversidade e de melhoria da qualidade de vida, o que representa a ressignificação e reforço do território.

Martins (1997, p. 15 - grifo do autor), ao discutir o tema (bastante polêmico) do surgimento de algo novo dentro das próprias contradições do sistema atual, na sua lógica 
de exclusão, traz uma ideia parecida, mesmo que com outras palavras: "Aos trabalhadores resta, por enquanto, na urgência dos problemas de sobrevivência, moverem-se no interior do possível estabelecido por essas limitações excludentes. E tentar a transformação social a partir daí [...]”. Mesmo que:

Os casos já conhecidos de "economia alternativa" no nível das comunidades e pequenos grupos são casos que indicam um ajustamento eficaz, do ponto de vista estritamente econômico, à lógica atual da economia dominante: a saída está na imaginação e na criatividade, que seria, no fundo, uma espécie de solução terceirizada (exatamente conforme o modelo que está sendo implantado, e não em oposição a ele). Não é por isso, obviamente, que a solução deve ser recusada, pois pode ser a única. (MARTINS, 1997, p. 13 - grifos do autor)

Há duas faces do turismo: como atividade hegemônica das empresas transnacionais e como projetos turísticos modestos que apresentam oportunidades para a comunidade hospedeira. Há 20 anos, o Curral tinha características da segunda face (mesmo que de maneira ambígua, já que estas duas faces constantemente se apresentam misturadas, com facetas cambiantes). Agora tem mais características da primeira. Rodrigues (2007, p. 17) afirma que:

É fundamental insistir que o território não é apenas espaço físico, palco das atividades humanas, tampouco é inerte. [...] definirá novas ações humanas, que poderão fortalecer ou desestruturar as territorialidades construídas.

Um elemento básico é procurar entender e atuar para a necessária autonomia dos sujeitos. Para isso, a ideia de desenvolvimento local serve como ferramenta. A escala denominada de "local" é flexível, pode ser a comunitária, a municipal ou a regional, com base no desenvolvimento que signifique maior autonomia para uma determinada população. Fazer uma análise crítica das ações que se propõem objetivando o "desenvolvimento local" é importante. Como escreve Martins (1997, pp. 20 - 21):

A verdade é que, em países como o Brasil, a retórica populista da exclusão, tão presente na fala dos agentes de pastoral, dos agentes políticos e dos agentes sindicais, não tem nenhuma eficácia ou quase nenhuma na afirmação de um ponto de vista alternativo conseqüente. Com facilidade, o outro lado captura o nosso discurso, as nossas propostas e até ultrapassa as nossas soluções, dando respostas (não importa quais) ao que nós dizemos que não tem resposta e quando dizemos que eles não têm resposta.

Durante as entrevistas constatou-se que falta a participação popular, porque a criação da associação do bairro por pessoas de fora não foi aceita pelos caiçaras. No item sobre identidade territorial, percebeu-se também que esta resistência às pessoas que não são caiçaras está ligada ao sentimento de que são discriminados por serem mais pobres. A escolaridade entre os caiçaras aumentou, mas que escolaridade é essa? Os próprios entrevistados consideram que a escola afastou os filhos da identidade cultural. 
Uma análise do projeto em andamento nas escolas municipais, tomando-se por base os livros didáticos, mostra algumas tentativas de trazer a cultura caiçara para o ensino formal. Por exemplo, o livro do $1^{\circ}$ ano do ensino fundamental, segundo bimestre (ILHABELA, 2011 b), traz quatro páginas com atividades contextualizadas a respeito do município: a contracapa traz uma lista de cachoeiras, praias, trilhas e tradições caiçaras. Nas tradições caiçaras aparecem apenas: 1) congada e festa de São Benedito; 2) festa de Santa Verônica; 3) festa de São Pedro; e 4) padroeira de Ilhabela - Nossa Senhora d'Ajuda e Bom Sucesso. Antes dos créditos aparece um pequeno artigo sobre Ilhabela histórica (pelo conteúdo, é um texto para ser lido pelo professor) com uma aquarela de Debret, do ano de 1827 (figura 3).

Figura 3 - Quadro de Debret da vila, reproduzido nos livros didáticos do ensino municipal

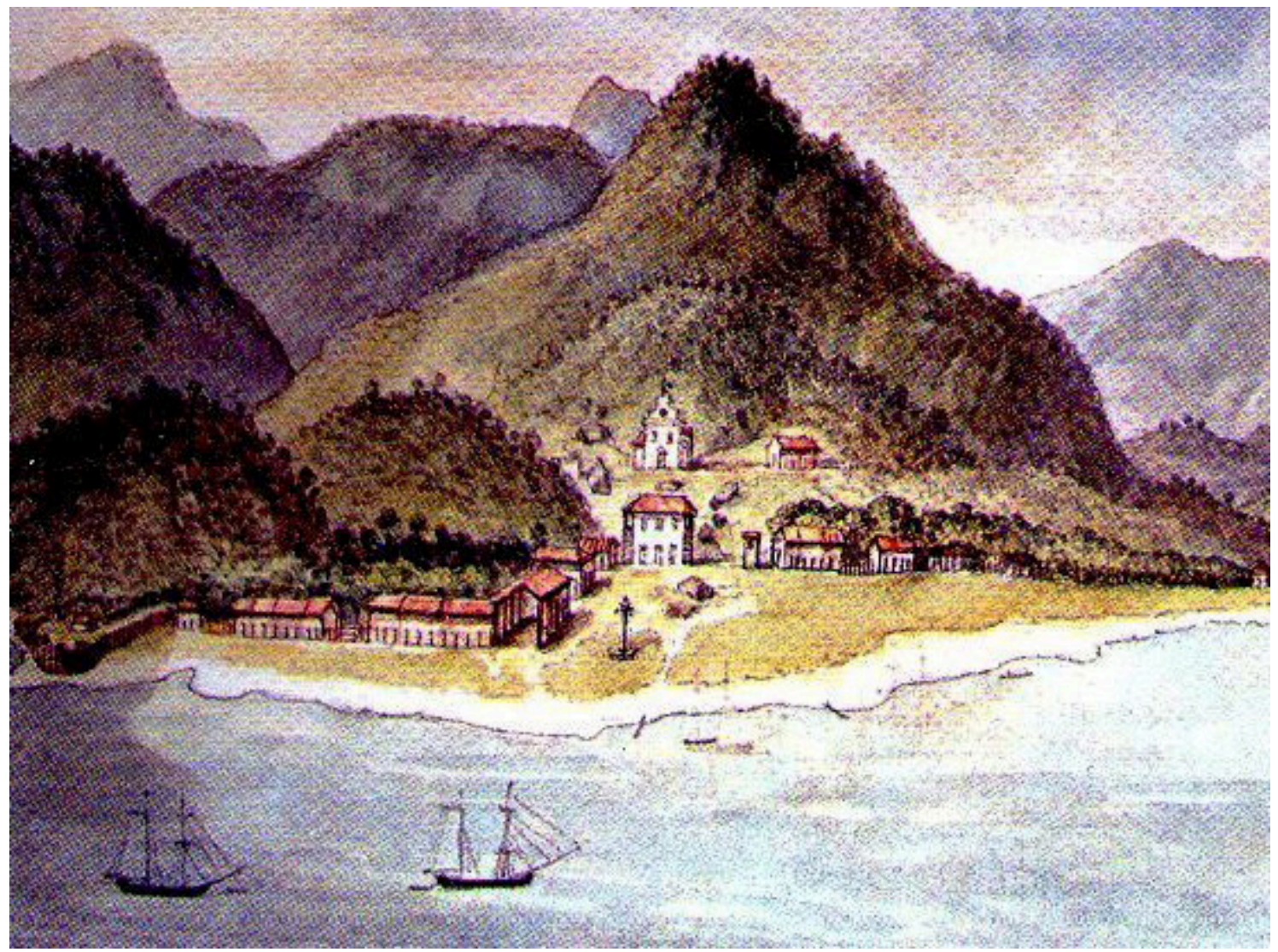

Fonte: I/habela, $2011 b$

Na página 56 pede-se que o aluno faça um desenho sobre a semana internacional da vela, valendo-se de algumas fotografias. Uma cruzadinha é solicitada com o auxílio de fotografias da congada, na página 56. Por fim, na página 65, há informações sobre datas festivas do bimestre. Em maio, de 9 a 15, ocorre a semana de cultura caiçara e festa de São Benedito na congada de Ilhabela. O mês de junho possui três festas: Santo Antônio, no bairro do Portinho, dia 10; São João Batista, bairro Perequê, dia 20; São Pedro e procissão marítima, vila, de 24 a 26. Por fim, em julho, de 2 a 9, a semana internacional de vela; e no 
dia 7, a festa de Santa Verônica, no Bonete. A entrevistada 10, ligada à secretaria municipal de educação, informa que:

E a gente montou um caderno de apoio que é um apostilado para Ilhabela. Mas qual foi a preocupação? Estar colocando Ilhabela inserida neste material de apoio. Foi o que nós fizemos. Então começa as capas, fotos que são utilizadas lá dentro, tem que colocar desenho, então por que não que este desenho seja pertinente ao mundo deles? Se você vai fazer a releitura de um quadro, por exemplo, por que não este quadro ser de um pintor da ilha? Foi uma coisa que nós conseguimos fazer, então o brasão da Ilhabela em todas as páginas, o hino na contracapa, então é uma forma que a gente achou de valorizar, resgatar. Até porque a empresa montou um site, sempre que ele vai fazer uma entrevista ou uma pesquisa para colocar aquilo no caderno de apoio [...].

Ressalvando que se trata de uma tentativa importante de trazer a cultura caiçara para as escolas municipais, ainda é algo pontual, em alguns aspectos trazendo a ideia da cultura como folclore.Entende-se que o que é necessário é muito mais complexo, tratando-se de uma mudança na epistemologia do conhecimento, na linha do que Morin (2001) chamou de "sete saberes necessários para a educação do futuro".

Solicitado pela UNESCO (Organização das Nações Unidas para a Educação, a Ciência e a Cultura) a criar um conjunto de reflexões sobre a educação do século XXI, Morin discute que a educação deve mostrar que não há conhecimento que não esteja, em algum grau, ameaçado pelo erro e pela ilusão. Afirma que um problema sempre ignorado é que o conhecimento deve ser capaz de apreender problemas globais e fundamentais para nele inserir os conhecimentos parciais e locais. Torna-se fundamental reconhecer a condição e a complexidade humana, pois o ser humano é, ao mesmo tempo, físico, biológico, psíquico, cultural, social e histórico.

Tal conhecimento entenderia a identidade territorial na sua complexidade inerente e o "ser caiçara" deixaria de ser visto apenas como algo do passado. O território em seus aspectos simbólicos passaria a ser compreendido e a urgência das políticas públicas relacionadas, inclusive a manutenção das formas antigas. Com relação à mudança da escola da Praia Grande, escola que era em frente ao mar, e passou a se localizar na encosta (como aconteceu com muitas moradias caiçaras), um indício das perdas das rugosidades, a mesma entrevistada informa:

O município deu o terreno e o estado fez a obra. Na gestão anterior. [...] Todo mundo que estava na Praia Grande teve que ir para o Bexiga, teve que ir de ônibus, para alguns foi bom, pra outros não etc. Mas estava ali muito próximo. Praia Grande. Bexiga, Curral, está ali. Um bairro coladinho no outro. Aos olhos dos alunos era uma vantagem porque a escola é muito grande, muito bonita, dois andares, encheu os olhos de todo mundo. Quando você vai para uma coisa muito melhor, você não sofre tanto. E aquele prédio, o estado doou para a prefeitura. Porque o Ana Leite antigo era do estado. E eles doaram para o município. [...] É, de frente para a praia, para a igrejinha [...] Foi quando foi feito o projeto de fazer um centro cultural e educacional [...] 
Reconhecer, na escala local, quais impactos ocorrerão com o turismo, tanto positivos quanto negativos, e, mais que isso, que grupos sociais ou categorias de sujeitos serão penalizados ou beneficiados com esses impactos é algo sempre necessário. No bairro pesquisado, o único item que trouxe um resultado claramente positivo foi um aumento do número de vagas para as ocupações formais e informais. Mesmo assim, é muito menor do que o declarado por alguns entrevistados, que calcularam uns 150 empregos apenas no resort, 50 apenas para os moradores do Curral. Talvez essa imagem de grande gerador de empregos seja consequência do início da construção do hotel, quando, segundo o entrevistado 11:

[...] 2005 [...] até 2009 que foi o período de construção do hotel [...] foi uma avalanche de acontecimentos ali, muita gente empregada, durante a obra ou o período dos meses finais da obra tinha mais de 300 pessoas na obra trabalhando. [...] foi assim uma coisa que eu nunca tinha presenciado na vida e não sei se vou presenciar de novo. A forma como foi feito, a velocidade com que foi feito, a quantidade de dinheiro que foi envolvido na história... Então eu acho assim que no lado social ali, de geração de empregos, de oportunidades foi uma coisa muito grande, com muita gente, que foi dada para o povo da Ilha, pelo menos na execução do hotel. Existia a fábrica de mosaicos, que só na fábrica de mosaicos era muita molecada... [...] a grande parte era do Curral, do Bexiga e da Praia Grande, gente lá do sul. E tudo molecada, na faixa dos 15 aos 20 anos de idade... Uma fábrica mesmo. Produção em série, era muita coisa, o hotel é muito grande, imagina todos os quartos, os banheiros, os banheiros sociais têm uma parede inteira com mosaico, o piso do restaurante, o restaurante deve ter uns 200 metros quadrados, o piso do restaurante todinho é mosaico, tem uma molecada de lá, entendeu, então assim nesse aspecto foi uma coisa nunca vista em Ilhabela, nunca imaginado, em termos, nesse sentido assim, o que gerou de movimento, de emprego e para toda mão de obra da ilha por que naquele período da construção do hotel, os caras bons da Ilhabela estavam envolvidos, o serralheiro, o marceneiro, o carpinteiro, como é que chama? O estampador lá, o cortineiro, o cara que mexe com bambu então, sabe, todo mundo... [...] Longe de mim imaginar, imaginar não, saber exatamente, isso aqui não é um dado, mas é um assuntamento meu aqui... Então a gente não está falando de... [...] De pouco dinheiro.

É possível, por este relato, imaginar o quanto a construção dinamizou a economia da ilha, na época. Porém, pelo que se constatou na análise de dados, atualmente apenas um número aproximado de 20 moradores do Curral trabalham no hotel. Além disso, o processo fez diminuir outras funções que eram desempenhadas pelos caiçaras, como a de caseiros (atualmente há menos 10 caseiros do que havia em 1991).

Enfim, compreender o território como “[...] fruto da interação entre relações sociais e controle do/pelo espaço, relações de poder em sentido amplo, ao mesmo tempo de forma mais concreta (dominação) e mais simbólica (um tipo de apropriação).” (HAESBAERT, 2010, p. 235), mostra que novas relações de poder foram criadas com base na instalação do resort na praia do Curral. E estas novas relações estão enfraquecendo as possibilidades do território como abrigo. 
Na busca do desenvolvimento local, Rodrigues (2007) propõe quatro marcos conceituais: 1) marco valórico - democracia - compromisso com os semelhantes; 2) marco material - pleno emprego com dignidade, tecnologias de baixo impacto e resgate dos saberes tradicionais; 3) marco sinérgico - projeto coletivo; 4) marco endógeno - priorizar a memória coletiva e o patrimônio.

Como se viu até agora, o que está ocorrendo no Curral está se afastando, cada vez mais, da ideia do desenvolvimento com base local. É necessário fortalecer o marco valórico, o marco material e o marco sinérgico - há especialmente ausência de um projeto coletivo.

\section{CONSIDERAÇÕES FINAIS}

Em uma síntese final, pode-se retornar à questão inicial, a relação entre a identidade territorial e o turismo de base local. Em primeiro lugar, entende-se que a identidade de projeto, que busca transformações na estrutura social, portanto a que não é conformista, como a identidade legitimadora, permitiria, em tese, um turismo apropriado pela comunidade, já que a identidade organiza significados.

O que foi constatado há 20 anos e que ainda se mantém hoje, entre os caiçaras do Curral, é um tipo de identidade territorial de resistência, já que o território é o principal elo para o "ser caiçara". Constatou-se nas entrevistas que a quase totalidade dos informantes remetem-se aos aspectos dapaisagem ao pensar na sua alteridade, entendendo que o "ser caiçara" está ligado a uma relação homem x natureza específica, ligada a um privilégio, o desfrute do mundo natural.

Entretanto, se até aqui a identidade caiçara é algo principalmente positivo, quando questionados a respeito de como as pessoas de fora entendem o "ser caiçara" a maioria das respostas passa a ter uma conotação pejorativa. Isto é, se internamente o significado é algo bom, os caiçaras do Curral entendem que são vistos com preconceito (preguiçosos, ignorantes, atrasados, inferiores etc.). Pode-se inferir que na relação de algumas décadas com o turismo muitas experiências negativas devem ter ocorrido, para que este tipo de resposta seja tão predominante, e que é necessária uma urgente mudança na relação turista $\mathrm{X}$ comunidade local para que o turismo de base local desejado ocorra. No relato das entrevistas, o turismo trouxe aspectos positivos (especialmente econômicos) e predominantemente negativos (excesso de turistas em relação à infraestrutura existente, problemas ambientais, os caiçaras perderam seu lugar e chegaram pessoas violentas). 
Constatou-se que a identidade territorial de resistência pode se transformar em identidade territorial de projeto, no que foi chamado de territórios zonais de resistência/ inovação, nos quais o sentimento de pertencimento cria uma interação entre as pessoas e um projeto inovador em comum. Fica então claro que está se falando de uma lógica contra hegemônica no turismo, uma lógica ligada às pequenas empresas do setor organizadas e administradas pela população local. Para isso, conhecer, valorizar e apoiar as especificidades do lugar pode ser uma contribuição como uma tarefa importante para os profissionais da Geografia ou de outra área do conhecimento que trabalhem com o planejamento do território.

\section{REFERÊNCIAS}

1. ABRAHÃO, M. H. M. B. Memória, narrativas e pesquisa autobiográfica. Revista História da Educação, UFRGS, v. 7, n. 14, pp. 79 - 95, Pelotas, set. 2003. Disponível em: http://dialnet. unirioja.es/ejemplar/315259. Acesso 08 nov. 2015.

2. CALVENTE, M. C. M. H. No território do azul-marinho: a busca do espaço caiçara. Dissertação (Mestrado em Geografia Humana). São Paulo : FFLCH - Universidade de São Paulo, 1993.

3. CASTELLS, M. O Poder da Identidade. São Paulo: Paz e Terra, 1999.

4. CiCONELlO, A. O desafio de eliminar o racismo no Brasil: a nova institucionalidade no combate à desigualdade racial. In: Oxfam International. From Poverty to Power: How ActiveCitzens and Effective States Can Change The World: Oxfam International, 2008. Disponível em: http://www.inesc.org.br/biblioteca/publicacoes/artigos/Racismo\%20-\%20texto\%20do\%20 Peck.pdf/view. Acesso 09 nov. 2015.

5. CUNHA, M. I. da. CONTA-ME AGORA! as narrativas como alternativas pedagógicas na pesquisa e no ensino. Revista da Faculdade de Educação, USP, v. 23, n. I-2, pp. 185 - 195, São Paulo, jan./dez. 1997. Disponível em: http://www.scielo.br/scielo.php?script=sci_ arttext\&pid=S0102-25551997000100010. Acesso 08 nov. 2015.

6. FRANÇA, A. A Ilha de São Sebastião - estudo de Geografia Humana. Tese de doutoramento, São Paulo, USP, Inst. de Geografia, 1951.

7. HAESBAERT, R. O Mito da Desterritorialização - do “fim dos Territórios" à Multiterritorialidade. $5^{a}$ ed. Rio de Janeiro: Bertrand Brasil, 2010.

8. __ Identidades territoriais. In: ROSENDAHL, Z.; CORREAA, R. L. Manifestações da Cultura no Espaço. Rio de Janeiro: edUERJ, 1999. pp. 169 - 190.

9. ILHABELA. Prefeitura Municipal. Notícias de Ilhabela. Disponível em: http://www.ilhabela. sp.gov.br/portugues/ver_conteudo_foto2.php?cod_conteudo=0004478. Acesso 22 set. $2011 \mathrm{a}$.

10. ___ Secretaria Municipal de Educação. Caderno de $1^{\circ}$ ano do EnsinoFundamental. $2^{\circ}$ bimestre. Vinhedo: Forma Escrita Projeto Editorial, 2011b. 
11. LEITE, F. Comunicação e cognição: os efeitos da propaganda contra-intuitiva no deslocamento de crenças e estereótipos. Ciências e Cognição.UFRJ, Rio de Janeiro, v. 13, pp. 131 - 141, 2008. Disponível em: http://www.cienciasecognicao.org/pdf/v13/m318223.pdf. Acesso 09 nov. 2015.

12. MARTELLI, A. C. Entrelaçando memória e experiência na tessitura da narrativa. Travessias, UNIOESTE, Cascavel, v. 1, n. 1, pp. 01 - 09, 2007. Disponível em: http://e-revista.unioeste. br/index.php/travessias/issue/archive. Acesso 08 nov. 2015.

13. MARTINS, J. de S. Exclusão social e a nova desigualdade. $4^{\text {a }}$ ed. São Paulo: Paulus, 1997.

14. MORIN, E. Os Sete Saberes necessários à Educação do Futuro. $3^{\mathrm{a}}$ ed. São Paulo: Cortez/Brasília: UNESCO, 2001.

15. RODRIGUES, A. B. Dúvida pontual[mensagem pessoal]. Mensagem recebida por <autor> em 28 abr. 2011.

16. . Turismo e fortalecimento das micro-economias locais - oportunidade de inserção social. In: BURNE, S. M. A.; DACHARY, A. C. (orgs.). Turismo y Desarrollo: crecimiento y pobreza. Puerto Vallarta: Universidad de Guadalajara; Universidad de Buenos Aires; Universidad Nacional de Mar del Plata, 2009. pp. 37 - 46.

17. . A. B. Território, patrimônio e turismo com base local - uma relação inequívoca. In: SEABRA, G. (org.). Turismo de Base Local - identidade cultural e desenvolvimento regional. João Pessoa: Universitária UFPB, 2007. pp. 15 - 29.

Artigo recebido em 10 de outubro de 2015.

Artigo aceito em 9 de dezembro de 2015. 